\title{
Possibilidades de atividades de matemática para estudantes na condição de surdocegueira
}

\section{Possibilities of mathematical activities for deafblindness students}

Felipe Moraes dos Santos ${ }^{1}$

Elielson Ribeiro de Sales ${ }^{2}$

\section{Resumo}

Esta produção expõe como tema geral a educação inclusiva, abordando possibilidades do ensino de matemática para estudantes na condição de surdocegueira embasado em momentos da história da matemática. Tendo como questão de pesquisa: Como elaborar atividades que possam ser atraentes ao aprendizado de Matemática por estudantes na condição de surdocegueira? Objetivamos analisar inerências às necessidades educacionais da pessoa com surdocegueira e reconhecer situações da história da matemática que possam ser-lhes atraentes, gerando proposta de atividade que auxiliem o professor, caso encontre-se com estudantes nessas condições. Para tal intento em nosso método, focamos uma abordagem de cunho bibliográfico e qualitativa com apontamentos de obras da educação de pessoas com surdocegueira, e obras da história da matemática que relatassem situações potencializadoras ao ensino de matemática para pessoas com surdocegueira. Assim, o referencial teórico desta pesquisa

\footnotetext{
1 Mestre em Educação Ciências e Matemáticas, pelo Instituto de Educação Matemática e Científica (IEMCI) - 2019, Especialista em Educação Especial na Perspectiva da Inclusão, pela Escola Superior da Amazônia (ESAMAZ) 2019. Graduado em Licenciatura Plena em Matemática pela Universidade Federal do Pará (UFPa) - 2017.

2 Possui graduação em Licenciatura Plena em Matemática pela Universidade do Estado do Pará (1996), mestrado em Educação em Ciências e Matemáticas pela Universidade Federal do Pará (2008) e doutorado em Educação Matemática pela Universidade Estadual Júlio de Mesquita Filho (2013). Atualmente é professor Adjunto II da Universidade Federal do Pará no Curso Licenciatura Integrada em Ciências, Matemática e Linguagens, professor do Programa de Pós-Graduação em Educação em Ciências e Matemáticas (PPGECM.
}

Interfaces da Educ., Paranaíba, v.11, n.31, p. 650 - 674, 2020

ISSN 2177-7691 
Possibilidades de atividades de matemática...

contemplou autores da educação matemática e da educação inclusiva. O estudo aponta como principais conclusões que há elementos na história da matemática que tem como base objetos tangiveis que assemelham-se às necessidades dos estudantes surdocegos em relação ao entendimento pelo toque, sendo possiveis de exequibilidade no ambiente educacional. Além disso, é exposta uma atividade adaptada que pode ser aplicada com estudantes com surdocegueira de variada faixa etária.

Palavras-chave: Educação. Ensino. Ischango. Matemática. Surdocegueira.

\begin{abstract}
This production presents as a general theme inclusive education, addressing the possibilities of teaching mathematics to students in the condition of deafblindness based on moments in the history of mathematics. Having as research question: How to elaborate activities that may be attractive to the learning of Mathematics by deafblind students? The objective is analyze the inherent educational needs of the deafblind person and to recognize situations in the history of mathematics that may be attractive to them, generating an activity proposal that will help the teacher if he meets students in these conditions. For this purpose in our method, we focus on a bibliographical and qualitative approach with notes of works of education of people with deafblindness, and works of the history of mathematics that reported potential situations to the teaching of mathematics for people with deafblindness. Thus, the theoretical framework of this research included authors of mathematical education and inclusive education. The study points out as main conclusions that there are elements in the history of mathematics that are based on tangible objects that resemble the needs of deafblind students in relation to the understanding by touch, being possible of feasibility in the educational environment. In addition, an adapted activity that can be applied to students with deafblindness of various age is exposed.
\end{abstract}

Keywords: Education. Teaching. Ischango. Mathematics. Deafblidness. 


\section{Introdução}

O primeiro atendimento educacional para pessoas com surdocegueira, segundo Camacho (2002) ocorreu na França em 1700, conhecido com Victoria Morriseau, perpassando por casos notáveis como a poetisa Bertha Callone e a conferencista Helen Keller (WATERHOUSE, 1977). Nos séculos XVIII e XIX evidencia-se que o principal foco dos professores à época era a comunicação e o aprendizado de atividades da vida cotidiana, conforme o livro de Lanson The Life and Education of Laura Bridgman de 1878 e reafirmados por Maia (2018).

Com os novos entendimentos educacionais a partir da Constituição Brasileira de 1988, que assegura em seu artigo 205 o direito de educação para todos (BRASIL, 1988), as pessoas com surdocegueira devem ser atendidas em instituições educacionais tendo convivência com colegas e conteúdos da educação básica. Temos assim um progresso educacional em relação à internação ou tutoria destes alunos em instituições específicas, como se pregava nos séculos XVIII e XIX. Além disso, se enfatiza a elaboração de estratégias para o ensino de pessoas com deficiência, conforme reconhece a Lei Federal n 13.146 de Julho de 2015.

Barros (2016) aponta a necessidade de conceituação de palavras e seu respectivo entendimento para aplicação em estudos científicos. Assim, o Grupo Brasil, um dos responsáveis por dar significado a terminologia surdocegueira no cenário nacional, apresentou em 2017 uma clarificação do termo, expondo que é

\footnotetext{
Uma deficiência única que apresenta perdas auditiva e visual concomitantemente, em diferentes graus, e que pode limitar a atividade da pessoa com surdocegueira e restringir sua participação em situações do cotidiano, cabendo à sociedade garantir-lhe diferentes formas de comunicação e Tecnologia Assistiva para que ela possa interagir com o meio social e o meio ambiente promovendo: acessibilidade, mobilidade urbana e uma vida social com qualidade (GRUPO BRASIL, 2017, p.1).
}

Diante de perfil tão singular inserido na escola, buscamos nos cursos de Guia Interprete e Instrutor Mediador, ofertados pela Associação Educacional para Multipladeficiência Ahimsa, em São Paulo, instituição de 
Possibilidades de atividades de matemática...

referência na América Latina, estratégias para entender a condição do aluno com surdocegueira, estabelecendo conexões entre a literatura da área, vivência e a prática de estratégias para o ensino.

$\mathrm{Na}$ escola, uma das disciplinas apresentadas é a matemática e nosso intento remete a apontar possibilidades ao ensino da matemática basilar para estudantes com surdocegueira. Observamos que a literatura referente ao atendimento para pessoas com surdocegueira e de aspectos da história da Matemática, nos conduzia para buscar similaridades em seus raciocínios gerando uma proposta que atendesse a necessidade do professor e do aluno.

Optamos pela história da matemática, em consonância com Mendes (2006) que referencia Fauvel (1991) no sentido de apontar diversas razões para uso em episódios pontuais destacando o aumento da motivação para aprendizagem da matemática e a humanização da matemática. Para este autor, o trabalho de Fauvel (1991) contribui significativamente a partir das proposições, pois elas se mostram interconectadas dando significado ao trabalho do professor e a aprendizagem dos alunos.

No presente estudo, propomos uma ação empírica em que é apresentado ao participante da pesquisa um objeto ou uma situação, por exemplo, um osso talhado. Intentamos que, o aluno perceba a situação como obra de um ser humano que viveu em determinada época e que não estava preparando-se para fazer uma prova, pois, como comenta Possani (2016), o homem não estava aprendendo matemática porque tinha uma tarefa a cumprir, ele estava vivendo a sua vida como ser humano, e aparentemente fez contagem.

Em face dos apontamentos expostos, levantamos uma questão como fio condutor deste estudo: Como elaborar atividades possam ser atraentes ao aprendizado de Matemática por estudantes com surdocegueira?

O objetivo geral deste escrito é analisar as necessidades educacionais da pessoa com surdocegueira e estabelecer conexões com situações da história da matemática que possam ser atraentes ao aluno, gerando propostas de atividades que auxiliem o professor a propor ações pedagógicas para estudantes nessas condições. 
Este estudo mostra-se relevante uma vez que remete a um contributo de proposta de ensino de matemática para pessoa com surdocegueira, pois conforme salienta Galvão (2016, p.13) "são em número muito reduzido, e isso agrava-se no tocante de alunos surdocegos, pois não foi encontrada nenhuma pesquisa voltada para o ensino da matemática para esses alunos". Sofrendo a adição de um estudo em geometria para surdocegos inserido no banco de dissertações e teses da capes no ano de 2017.

\section{Métodos}

Optamos pela pesquisa bibliográfica, que de acordo com Fonseca (2002), é feita a partir do levantamento de referências teóricas já analisadas e publicadas por meios escritos e eletrônicos, ou seja, literaturas que sejam pertinentes para o desenvolvimento do trabalho. Sendo assim, pode-se dizer que esta pesquisa é de cunho bibliográfico, uma vez que foi constituída a partir do levantamento e de leituras de artigos, resenhas e dissertações referentes a educação de pessoas com surdocegueira, bem como registros da história da matemática.

Entende-se que o estudo também assume um caráter qualitativo e segundo Córdova (2009), consiste na explicação e reflexão dos fatos. Por meio de um objeto de amostra que leva a compreensão de determinadas informações acerca da pesquisa, já que se faz necessário a presença de significante e significado.

Representativamente, os textos são o significante e através deles serão obtidos os significados, relativos às reflexões a partir das investigações de uma situação-problema, com o intuito de inferir dados expressivos de metodologias para os alunos com surdocegueira.

De acordo com Minayo (2001), se dois tipos de pesquisas estão em um mesmo trabalho elas relacionam-se, tendo como consequência a interação das duas formas de pesquisas. Para que não haja dicotomias, a pesquisa bibliográfica completará a pesquisa qualitativa, já que precisamos do referencial teórico para compreendermos o objeto de estudo.

\section{Referencial teórico}

Interfaces da Educ., Paranaíba, v.11, n.31, p. 650 - 674, 2020 
Esta seção contará com o aprofundamento teórico conceitual sobre a surdocegueira expondo as diferentes possibilidades desta deficiência, iremos expor também o toque como ferramenta natural para entendimento de ambientes e situações para estas pessoas, alguns métodos de comunicação para esse público, finalizando com a consciência do saber matemático e seu principio de contagem primitiva.

\title{
Combinações da surdocegueira
}

Conforme comentado, a definição de surdocegueira expõe perda auditiva e visual concomitante (MAIA, 2010), ou seja, temos um leque de possibilidades, ou um arranjo combinatório que pode ser gerado envolvendo situações visuais e situações auditivas. No quesito situações visuais o professor Antônio Conde (2016), em nome do Instituto Benjamin Constant (IBC) comenta,

\begin{abstract}
Uma pessoa é considerada cega se corresponde a um dos critérios seguintes: a visão corrigida do melhor dos seus olhos é de 20/200 ou menos, isto é, se ela pode ver a 20 pés (6 metros) o que uma pessoa de visão normal pode ver a 200 pés (60 metros), ou se o diâmetro mais largo do seu campo visual subentende um arco não maior de $20^{\circ}$, ainda que sua acuidade visual nesse estreito campo possa ser superior a 20/200. Esse campo visual restrito é muitas vezes chamado "visão em túnel" ou "em ponta de alfinete", e a essas definições chamam alguns "cegueira legal" ou "cegueira econômica". Nesse contexto, caracteriza-se como portador de visão subnormal ou baixa visão aquele que possui acuidade visual de 6/60 e 18/60 (escala métrica) e/ou um campo visual entre $20^{\circ}$ e $50^{\circ}$. (CONDE, 2016, p.1).
\end{abstract}

De acordo com o apontamento do IBC, pode-se assumir que na deficiência visual temos a pessoa que é cega, podendo ou não perceber a incidência de luz, as pessoas com baixa visão, que subdividem-se em visão em alfinete, quando tem-se o foco no centro dos olhos em um ângulo ínfimo, a visão central, onde o ângulo visual é maior no centro dos olhos e a visão periférica, quando tem-se somente visão nas laterais dos olhos.

Trazendo de forma mais didática ao cenário docente, Moraes (2016) apresenta uma ilustração (figura 1) envolvendo a fala de Conde. Em vermelho o arco de visão que corresponde a classificação de cegueira, que conforme foi explanado compreende um campo menor ou igual a $20^{\circ}$. 
Compreende-se pela ilustração que pessoas que apresentam resquícios de visão podem ser consideradas cegas. Em azul temos o arco de visão subnormal, nota-se que o novo arco compreende $30^{\circ}$, que somado aos $20^{\circ}$ anteriores resulta em um ângulo de variância de $50^{\circ}$, decorrendo assim na classificação de baixa visão.

Figura 1 - Campo visual comparativo entre baixa visão e cegueira.

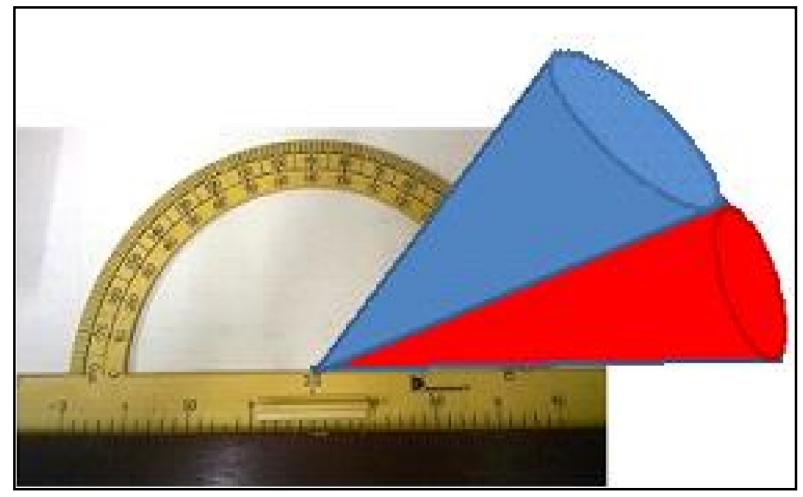

Fonte: Moraes (2016)

No quesito perdas auditivas temos variâncias similares a da cegueira. Conforme o local da lesão no sistema auditivo ocorrem diferentes classificações, a saber, a Condutiva, onde a alteração encontra-se na orelha externa causando problemas na condução do som; a Sensorioneural que atinge o nivel sensorial, acontecendo desde lesões no órgão de córtex, responsável por converter as vibrações sonoras em estimulos nervosos chegando até o córtex cerebral, sendo praticamente irreversivel; a Mista, onde as alterações encontram-se tanto na orelha externa como na interna, podendo ser gerada por má formação craniana envolvendo fatores genéticos que acometem os ossículos como o martelo, bigorna e estribo; e finalmente a Central, quando as alterações encontram-se desde o tronco encefálico até as regiões subcortiçais, sendo totalmente irreversível, segundo Bevilacqua (1998).

Além dessa classificação temos outra que refere-se ao grau de comprometimento, sendo medida em decibéis $(\mathrm{dB})$ que podem variar dependendo da faixa etária da pessoa. O grau leva em consideração os 
limiares tonais, que são definidos como a menor intensidade do som que o indivíduo consegue detectar. (BEVILACQUA, 1998).

Segundo a escala da deficiência auditiva publicada pela World Health Organization (WHO) o limiar para crianças é

Sem deficiência auditiva: l'imiar tonal até $15 \mathrm{~dB}$;

Deficiência auditiva leve: limiar tonal entre 16 e $30 \mathrm{~dB}$;

Deficiência auditiva moderada: limiar tonal entre 31 e $60 \mathrm{~dB}$;

Deficiência auditiva severa: limiar tonal entre 61 e $90 \mathrm{~dB}$;

Deficiência auditiva profunda: limiar tonal acima de $91 \mathrm{~dB}$ (WHO, 2014, s.p).

A classificação para adultos é:

Sem deficiência auditiva: limiar tonal até $25 \mathrm{~dB}$;

Deficiência auditiva leve: limiar tonal entre 26 e $40 \mathrm{~dB}$;

Deficiência auditiva moderada: limiar tonal entre 41 e $60 \mathrm{~dB}$;

Deficiência auditiva severa: limiar tonal entre 61 e $90 \mathrm{~dB}$;

Deficiência auditiva profunda: limiar tonal acima de 91 dB" (WHO, 2014, s.p).

Com os dados obtidos sobre as classificações de surdez e cegueira pode-se fazer diferentes combinações de situações que são consideradas surdocegueira, por exemplo, uma pessoa cega com deficiência auditiva severa é surdocega, uma pessoa surda com visão em alfinete é considerada surdocega, assim não é necessário que uma pessoa seja totalmente cega e totalmente surda para ser considerada surdocega.

Após este momento é necessário comentar que a surdocegueira pode ser classificada em duas situações, que são a surdocegueira pré linguística e a surdocegueira pós linguística.

O Grupo Brasil (2008, p.12) explica que a "surdocegueira prélinguística é a terminologia adotada para identificar pessoas que nascem surdocegas e/ou adquire a surdocegueira na mais tenra idade, ou seja, antes da aquisição de uma língua". Também conhecida como surdocegueira congênita, ocorre na fase inicial de vida da criança, por vezes ocorre a perda de audição e visão durante a gestação. Nesse caso a criança surdocega tem dificuldade em organizar em sua mente o mundo em que vive e principalmente em relacionar-se com as pessoas. O Grupo Brasil salienta 
que a superação destes primeiros momentos pode ocorrer se a criança for estimulada em atendimentos específicos (GRUPO BRASIL, 2000).

Novamente o Grupo Brasil (2008, p.12) especifica que "A denominação surdocegueira pós-linguística é utilizada para designar pessoas, crianças, jovem ou adulto, que adquirem a surdocegueira após a aquisição de uma língua (português ou LIBRAS)" (2008, p.12). Quando uma pessoa torna-se surdocega após a aquisição de linguagem dizemos que ela foi acometida de surdocegueira.

Alguns dos fatores que podem fazer a pessoa ser acometida de surdocegueira é ter perda total ou parcial de visão e audição devido a traumas ou patologias ou já nascer surdo ou cego e no decorrer da vida ser acometido de cegueira ou surdez devido fatores hereditários.

\section{O toque como ferramenta natural}

Em virtude das especificidades da condição de surdocego faz-se necessário o uso de estratégias para estabelecer a comunicação e tentar sanar os prejuízos apresentados no desenvolvimento da pessoa com surdocegueira, tanto em questões sociais como educacionais.

Nascimento (2003) explica que a surdocegueira proporciona obstáculos para o desenvolvimento escolar e autônomo do estudante surdocego, sendo necessário atividades que promovam o desenvolvimento de suas potencialidades, sendo o toque a ferramenta de maior aceitabilidade inicial.

Nicholas (2010) ao colocar que o tato é o sentido mais primitivo desenvolvido na formação biológica do ser humano quando comparado a visão e a audição, entrando em funcionamento por volta da oitava semana de gestação e permanecendo com suas atividades perceptivas até o fim da existência humana.

Para ilustrar as associações que o cérebro processa pelo toque em diferentes partes do corpo, recorremos ao homúnculo sensorial (figura 2), que consiste em uma versão distorcida do corpo humano relacionada ao mapa sensorial de áreas do cérebro incluindo fibras nervosas, lobo pariental 
e córtex cerebral (MARIEB, 2007), ou seja, é uma representação heurística do corpo dentro do cérebro.

Figura 2 - Homúnculo Sensorial

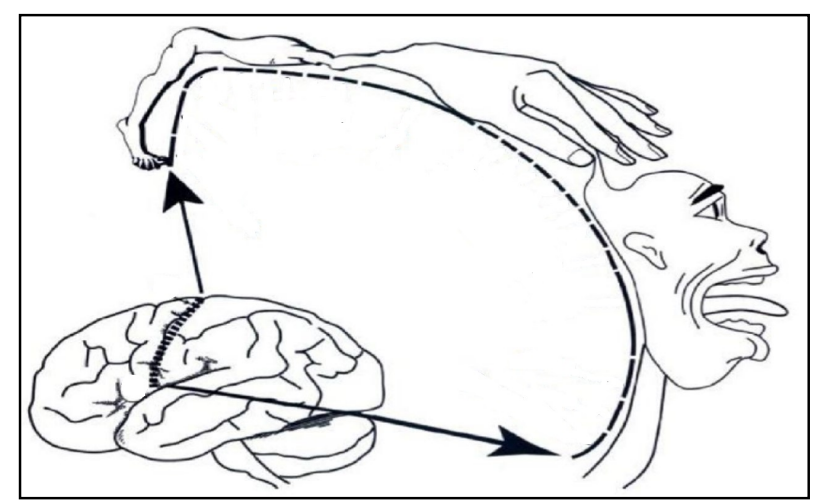

Fonte: Ahimsa (2011)

O conjunto das estruturas do cérebro estão diretamente ligadas com as emoções, ao comportamento e a memória, Nicholas (2010) salienta que o processamento de estímulos táteis encontra-se intimamente relacionado ao processamento das informações obtidas pela percepção espacial dos objetos.

Em virtude das possibilidades que a percepção tátil promove ao ser humano os estudos em surdocegueira baseiam seu processo inicial de comunicação pelo toque, havendo os que abordam a comunicação e a intervenção com surdocegos pré-linguísticos e pós-linguísticos,

Dentre os estudos consultamos a série "Surdocegueira e Deficiência Múltipla Sensorial” publicada em 2005 pelo Grupo Brasil, bem como "Estratégias de ensino para favorecer o aprendizado de pessoas com Surdocegueira e Deficiência Múltipla Sensorial" publicado em associação com a Canadian International Development Agency, que aponta aspectos de ressignificação, estratégias de ensino, ambiente reativo, sugestões para o desenvolvimento da aprendizagem. 


\section{Alguns métodos para comunicação com surdocegos}

A série Surdocegueira e Deficiência Múltipla Sensorial comenta como deve ser o atendimento inicial para pessoas com surdocegueira, expondo as experiências de professores que dedicam-se a esse estudo, além de contar com arquivos fotográficos disponibilizados pela Ahimsa e o Grupo Brasil. A série mantém-se atual apesar do ano de publicação, a seguir apresentamos algumas explicações da versão impressa do ano de 2005.

$\mathrm{Na}$ cartilha Surdocego Pré-linguístico os autores explicam que não apresenta importância as diferentes intensidades de perdas dentro da surdocegueira, mas devemos dar ênfase a funcionalidade das pessoas com surdocegueira (GRUPO BRASIL, 2005).

A funcionalidade inicia-se com a comunicação, pois é através dela que viabiliza-se as relações com o exterior, permitindo obter e compartilhar informações, não ficando restrito somente a fala, mas também sendo expressa por movimentos corporais. Um fator primordial ao sucesso nas interações é promover à pessoa surdocega o acesso ao lúdico, ao palpável, ao perceptivel, tanto físico quanto virtual.

O surdocego pós-liguistico já apresenta uma linguagem estabelecida, podendo ser a linguagem oralizada, língua de sinais ou uso do Braille como comunicação tátil. O Grupo Brasil (2005) explica que quando atendemos um surdocego pós-linguístico devemos verificar se há existência de resíduos visuais, acuidade visual e campo visual, pois destes possibilita-se elaborar métodos que possam ser mais adequados à situação da pessoa. Além disso, devemos dar atenção ao nivel de escolaridade que a pessoa encontra-se, a respeito do domínio da língua de sinais ou do Braille. No caso da pessoa não alfabetizada temos como alternativa utilizar objetos de referência similar aos utilizados para as pessoas pré-linguísticas.

Um fator que salientamos é o apontamento sobre a idade da pessoa. Segundo o Grupo Brasil (2005, p.15) "temos de ter claro que o ser humano tem diferentes motivações e interesses segundo a sua idade. Isto também é aplicável aos surdocegos. Não será o mesmo se a pessoa é adolescente, adulta ou criança”. Assim, a cada momento da vida do ser humano temos de explorar as potencialidades que ele apresenta e, para tal exploração devemos Interfaces da Educ., Paranaíba, v.11, n.31, p. 650 - 674, 2020 
verificar qual a melhor forma de comunicação para a pessoa que antes fora cega ou surda.

$\mathrm{Na}$ situação de uma pessoa que antes de ser acometida pela surdocegueira já apresentava cegueira, para os casos em que conhecesse, noções do sistema Braille, nos valeremos deste aprendizado para estabelecer comunicação.

Com a memória do código Braille pelo aluno com surdocegueira o professor pode realizar comunicação a partir da leitura e da escrita nas mãos da pessoa surdocega conhecida como Braille tátil. Basicamente, consiste em codificação e decodificação com uso dos dedos indicativo e o médio formando a cela braile nas falanges de seus dedos e baixando; a seguir o professor toca as falanges do aluno similar ao punção que punciona o papel. Na sequência apresentamos ilustrativamente (Figura 3) como seria a escrita da palavra "soma".

Figura 3 - Representação da palavra soma no método Braille

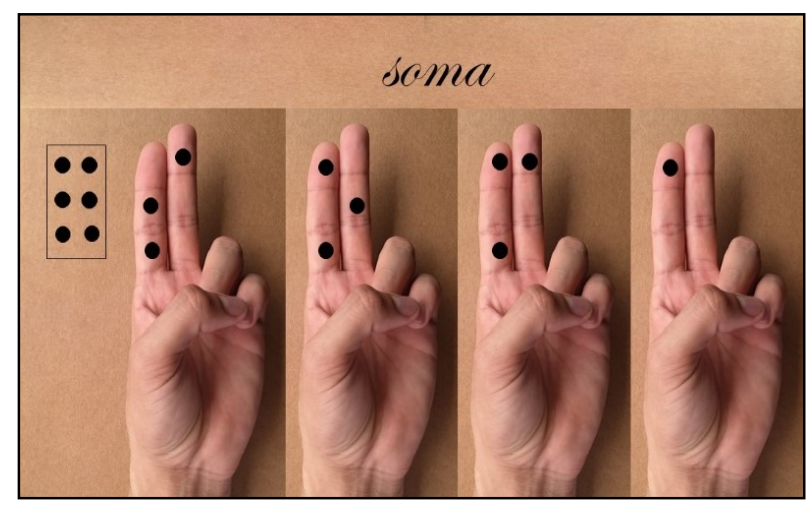

Fonte: Acervo do autor

Outro método interessante de comunicação ocorre quando a pessoa tem resquícios de audição. Valorizando as remanescências utilizamos a lingua oral simplificada, que consiste na recepção de uma mensagem dita por um interlocutor mediante o uso pela pessoa surdocega de um aparelho de amplificação sonora (GRUPO BRASIL, 2005).

No caso da pessoa com surdocegueira que anteriormente foi surda, aplicamos o método chamado de Libras tátil, que tem sua base na Língua Brasileira de Sinais (Libras), que é a lingua dos surdos do Brasil, conforme mostra a Lei $n^{\circ} 10.436 / 2002$. Brasil comenta que,

Interfaces da Educ., Paranaíba, v.11, n.31, p. 650 - 674, 2020 
Entende-se como Lingua Brasileira de Sinais - Libras a forma de comunicação e expressão, em que o sistema lingüístico de natureza visual motora, com estrutura gramatical própria, constituem um sistema lingüístico de transmissão de idéias e fatos, oriundos de comunidades de pessoas surdas do Brasil (BRASIL, 2002, s.p)

A Libras tátil consiste em que a pessoa com surdocegueira coloque suas mãos junto as mãos do interprete e perceba pelo tato os sinais que estão sendo feitos (figura 4).

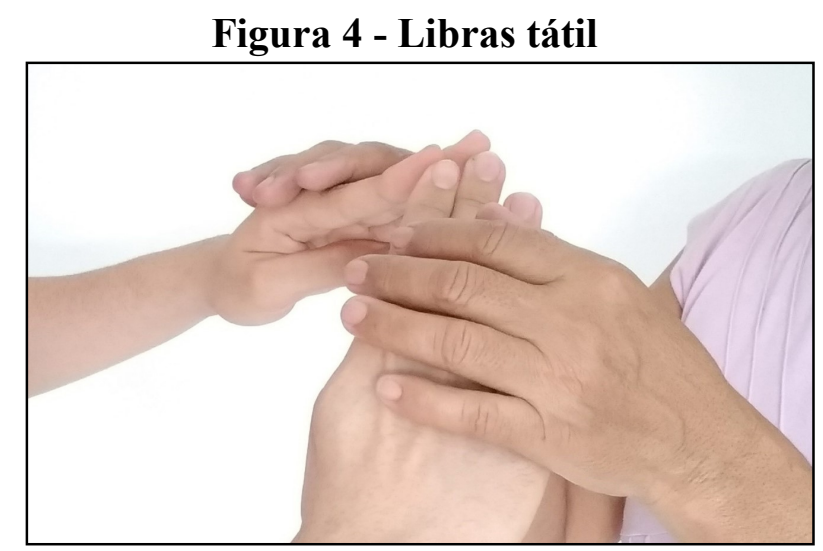

Fonte: Acervo do autor

Valendo-se ainda da língua de sinais, podemos utilizá-la como auxilio para pessoas com surdocegueira e seu campo visual reduzido. Para tal, buscamos em qual parte dos olhos a pessoa apresenta resquício visual, podendo ser a visão central ou periférica. Quando a pessoa surdocega encontra o foco de visão iniciamos o uso da língua de sinais em um campo de visão reduzido, ou seja, em um campo espacial menor do que o usual da lingua de sinais.

Com os apontamentos citados, inferimos que em sua maioria é valorizada a importância do tato e da comunicação como ferramenta de aquisição de conhecimento e relações com o mundo exterior, sendo de grande valia o seu uso em propostas de ensino para pessoas com surdocegueira.

Além disso, Petersen (2011) comenta as bases para elaboração de um Programa Educacional Individual (PEI) para o aluno com surdocegueira, baseado na publicação Assessment and making individual plans for learners that are deafblind. A autora explica que devido a complexidade da surdocegueira é necessário avaliar três diferentes níveis a saber, avaliação Interfaces da Educ., Paranaíba, v.11, n.31, p. 650 - 674, 2020 
médica, que contém as necessidades médicas da pessoa, avaliação funcional, que consiste em saber as potencialidades da pessoa dentre elas as comunicativas e a avaliação de vida diária, ou seja, consegue-se realizar tarefas como arrumar a cama (PETERSEN, 2011).

\section{A consciência do saber matemático}

Em virtude da necessidade que os estudantes com surdocegueira tem em aprender utilizando percepções táteis e sensoriais, nossa busca na bibliografia da história da matemática deteve-se principalmente em situações que pudessemos reelaborar para a sala de aula, com ênfase na construção histórica da matemática básica, com atenção especial à contagem.

Segundo Bourbaki (1939) para que dois conjuntos tenham mesma cardinalidade, cada conjunto deve ter um par no outro conjunto,. Essa técnica ficou conhecida como correspondência biunivoca e tal comparação foi utilizada pelo homem primitivo inicialmente em situações reais, por exemplo, em situações de troca entre tribos, tornando-se possivel estabelecer relações quantitativas entre grupos de objetos, proporcionando menos prejuízo para determinada parte.

Nota-se ainda que nas origens da humanidade não tínhamos o conceito de número no campo da abstração. Ifrah (1959) comenta que o número na gênese era "sentido", similar a como sentimos os odores, o ruído, a presença de alguém ou alguma coisa no exterior sendo uma percepção direta do número, ou mais simplesmente, uma sensação numérica. A correspondência biunivoca (figura 5) fazia-se necessário pensar para avaliar qual situação comercial seria mais vantajosa para a ocasião, sendo essa uma relação que não requeria o conceito de número abstrato. (DEPMAN, 1965).

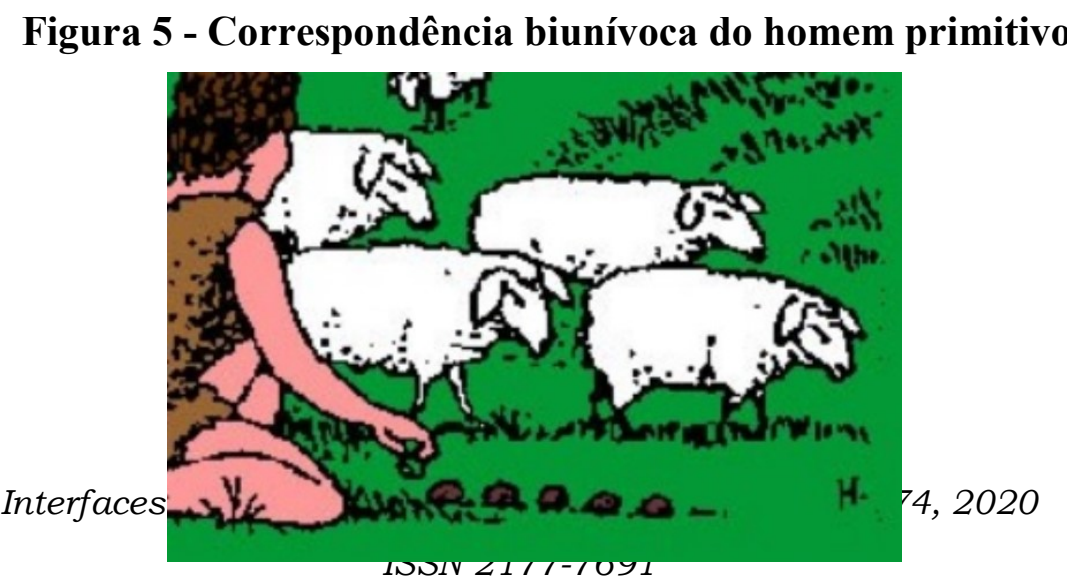


Fonte: Miranda (2020)

Outra situação de empregabilidade destaca-se no Paleolitico Inferior ou Período da Pedra Lascada, compreendido entre 2.500.000 - 300.000 antes de Cristo (a.C), onde o homem primitivo necessitava de noções de maior e menor ao controlar o crescimento de um rebanho, nessa situação o homem valia-se de lascamentos em ossos, onde um traço em um osso significava um animal (SILVA, 2006).

Referência importante a ser citada para este conhecimento é a descoberta do osso de Ischango, (Figura 6), datado do Paleolitico Superior, aproximadamente 20.000 - 10.000 a.C. Trata-se da fibula de um babuino com um pedaço de quartzo incrustado em uma ponta, supostamente utilizado para gravar. A revista Scientific American em sua edição de junho de 1962 explica que os cientistas afirmam que as agrupações dos traços indicam uma compreensão aritmética, que vai além da contagem.

Figura 6 - Osso de Ischango

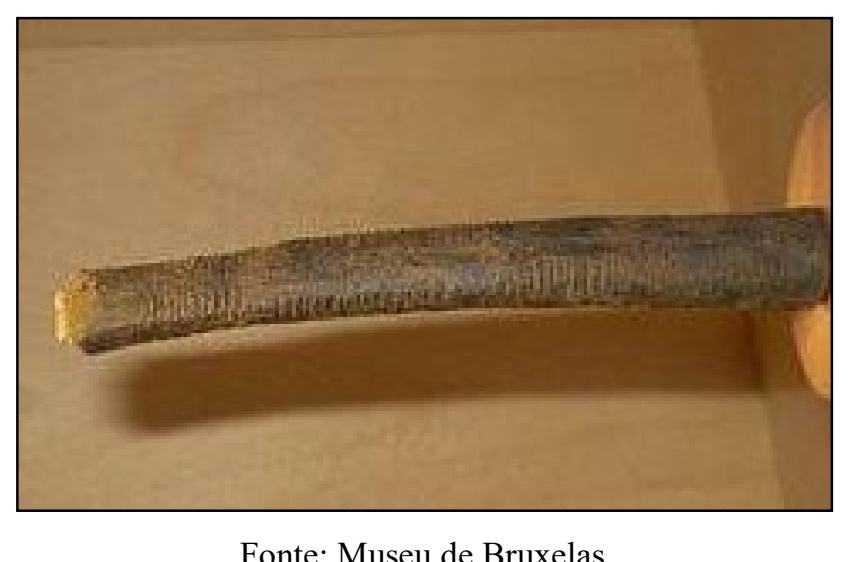

Tratando mais profundamente a questão matemática, o pesquisador PHD Olivier Keller em seu préhistoire de la Geométrie: le problèm des sources (KELLER, 2005) explica que o osso de Ischango pode ter sido talhado para estabelecer um sistema numérico (Figura 7).

Figura 7 - Interpretação dos símbolos no osso à luz dos nossos dias

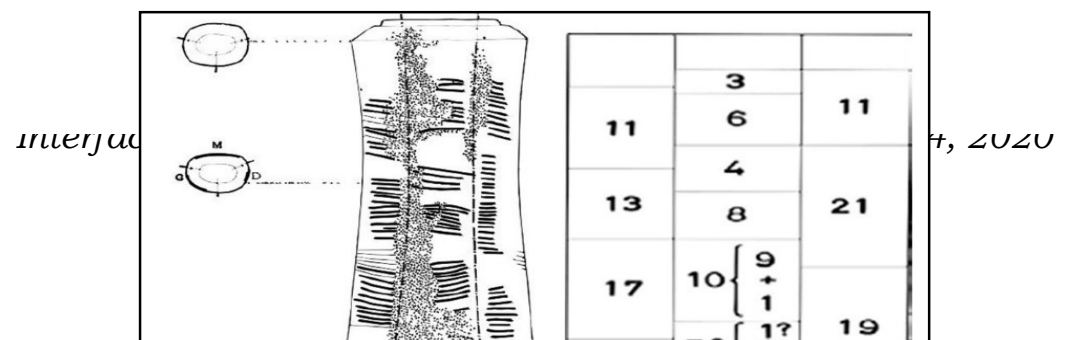


Ao longo da história diferentes povos desenvolveram métodos concretos de contagem e, ae mente: Dirk Huylebrouck são de uma genialidade que impressiona até em dias atuais os mais destacados pesquisadores, como o caso de contagem utilizando a falange proximal, a falange média e a falange distal adotado pelos babilônicos, que não só se aplicavam a contabilidade como também as transações comerciais.

\section{Proposta de atividade}

$\mathrm{Na}$ análise dos princípios da matemática humana percebe-se que o homem valeu-se da percepção tátil e manipulação de material concreto no desenvolvimento da matemática, e é baseado neste conhecimento que propomos algumas relações que podem ser aplicadas em atividades com estudantes com surdocegueira. Conforme explicitado anteriormente essas pessoas tem necessidade do contato tátil em grande parte de seus aprendizados, então nada mais adequado do que cerzir o conhecimento matemático concreto com a necessidade das pessoas com surdocegueira.

Nessa proposta, consideramos que a pessoa com surdocegueira pré ou pós-linguística está em seus princípios de entendimento das disciplinas escolares. Inicialmente tornar-se-á necessário a sondagem de informações para traçarmos o perfil do aluno. Assim, temos de elaborar um PEI com a avaliação médica, avaliação funcional e avaliação da vida diária do estudante. Interseccionando este momento e sondando quais são os conhecimentos prévios da pessoa com surdocegueira na questão de conhecimento matemático.

A posteriori, segundo o perfil traçado, introduzimos alguns recortes históricos para envolver o estudante, mostrando para ele que seres humanos, assim como ele, há 20.000 anos já faziam contagem, desse modo não apresentamos o conceito imediatamente, mas, explicando os detalhes até que o conceito evidencie-se.

Interfaces da Educ., Paranaíba, v.11, n.31, p. 650 - 674, 2020 
Chassot (2001) comenta que

Há necessidade de uma busca de um ensino cada vez mais marcado pela historicidade. Ao invés de apresentarmos o conhecimento pronto, é preciso resgatar os rascunhos. Também é preciso envolver alunos e alunas em atividades que busquem ligações com seu passado próximo ou remoto (CHASSOT, 2001, p.99).

As informações devem ser apresentadas ao estudante com surdocegueira através do canal comunicativo que melhor convir ao aluno, podendo ser, por exemplo, Libras tátil, Braille tátil, ou o método Tadoma, neste a pessoa com surdocegueira coloca os dedos nos lábios do interprete e a outra mão no pescoço deste, assim sente as vibrações vocais da fala. Assim nessa proposta comentaremos sobre a origem dos números naturais e as relações biunívocas que o homem primitivo utilizava, similar a situação de cinco peixes para cinco pedras conforme exposto por Eves (1990).

Aproximando a situação da contagem à materiais mais próximos da vivência do aluno utilizando frutas e pequenas pedras polidas (Figura 8).

\section{Figura 8 Relação entre maças e pedras}

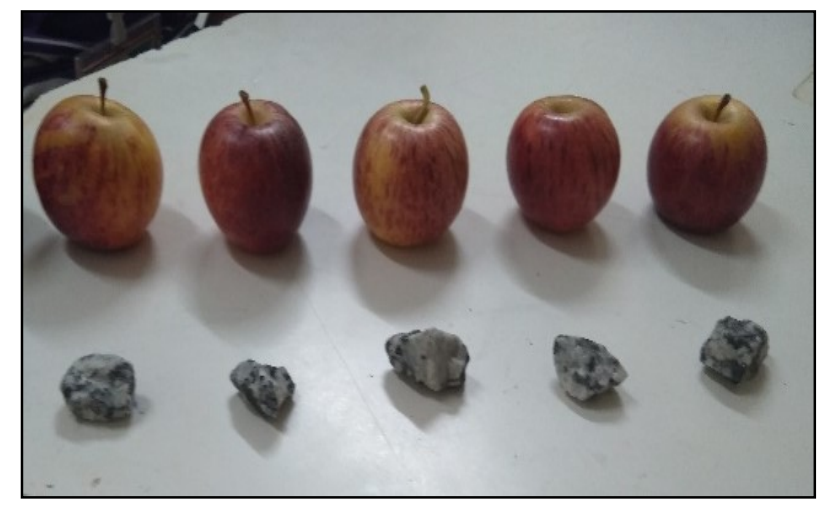

Fonte: Acervo do autor

O IBC (2018) comenta em seu escrito sobre o uso de materiais táteis que, os objetos que serão utilizados em atividades escolares com alunos cegos e surdocegos devem prezar por não oferecer perigo às falanges dos dedos dos estudantes, pois este é um dos canais comunicativos dos alunos, devendo evitar o dano.

Como queremos estimular o raciocínio do estudante realizamos perguntas tais como: "Você sabe como os seres humanos sabiam as Interfaces da Educ., Paranaíba, v.11, n.31, p. 650 - 674, 2020 
quantidades na antiguidade?" Podemos indagar também "Será que os números sempre existiram? Como eram os primeiros números?”. Ao vincular as perguntas e expor os objetos concretos vamos em direção dos Parâmetros Curriculares Nacionais (PCN's) que afirmam que para muitos alunos

\begin{abstract}
a matemática era uma matéria dificil e que seu estudo se resume em decorar uma série de fatos matemáticos, sem compreendê-los e sem perceber suas implicações e que isso lhe será de pouca utilidade. Tal constatação os leva a assumir atitudes bastante negativas, que se manifestam no desinteresse, na falta de empenho e mesmo na pouca preocupação diante dos resultados insatisfatórios ou nos sentimentos de insegurança, bloqueio e até em certa convicção de que são incompetentes para aprendê-la, o que os leva a se afastar da matemática em situações na vida futura (PCN's, 1998, p.79)
\end{abstract}

Com intenção de evitar o desinteresse, que por vezes acomete também os estudantes com surdocegueira (MAIA, 2010) é que vinculamos o objeto, a história da matemática e a matemática, coroado pela linguagem que expressa as potencialidades do momento.

Criamos a relação com o estudante ao apresentar uma maça para uma pedrinha, até chegarmos ao conjunto de cinco maças e cinco pedrinhas, que futuramente podem ser transpostos para os dedos da mão que totalizam cinco dedos e uma mão, similar ao que a história da matemática prega ter sido o princípio da contagem (EVES, 1990) tornando as atividades mais palpáveis para o estudante com surdocegueira.

Podemos solicitar ao aluno que realize as primeiras lições de agrupamento de soma e subtração contando em paralelo a história do por que a necessidade das quantidades e em sequência, expor o conceito de zero ao estudante. Seguindo a linha de raciocínio vamos criando situações que cheguem ao zero, por exemplo, três menos três que resulta em zero. Aqui não nos deteremos sobre o zero e suas diferentes definições na matemática, nos apoiaremos apenas na ideia de ausência, de vazio. Com o entendimento das quantidades e dos algarismos, essa etapa torna-se mais simples para o estudante, tendo um significado mais compreensivel, Ausubel (2002) comenta sobre essa questão que

La importancia de tener ideas pertinentes o apropriadas em algun outro sentido ya estabelecidas y disponibles em la estrutura cognitiva para hacer que las nuevas ideas logicamente significativas Interfaces da Educ., Paranaíba, v.11, n.31, p. 650 - 674, 2020 
y que las nuevas ideas potencialmente significativas sean realmente significativas (es decir, que produzcan nuevos significados), ademas de ofrecerles um anclage estable. (AUSUBEL, 2002, p. 41).

Então com o conhecimento já estabelecido de quantidades de um a nove é mais oportuno para o entendimento do incremento do zero e suas representatividades de dezenas.

Por conseguinte, passaremos para uma segunda atividade que trabalhe quantidades acima de nove. Para tal intuito nos valeremos de réplicas de ossos talhados, que assemelhem-se ao período paleolítico inferior. Segundo Ifrah (1959) o homem primitivo não iria andar com um saco de pedregulhos de baixo do braço, conforme os rebanhos ou outras quantidades foram aumentando ele buscou formas de condensar as quantidades em objetos, que chegara até os nossos dias, como o caso do osso de Ischango.

Utilizando uma réplica deste osso ou de um similar expomos para o estudante com surdocegueira as ranhuras na peça, sendo que cada uma ranhura equivale a uma unidade (Figura 9).

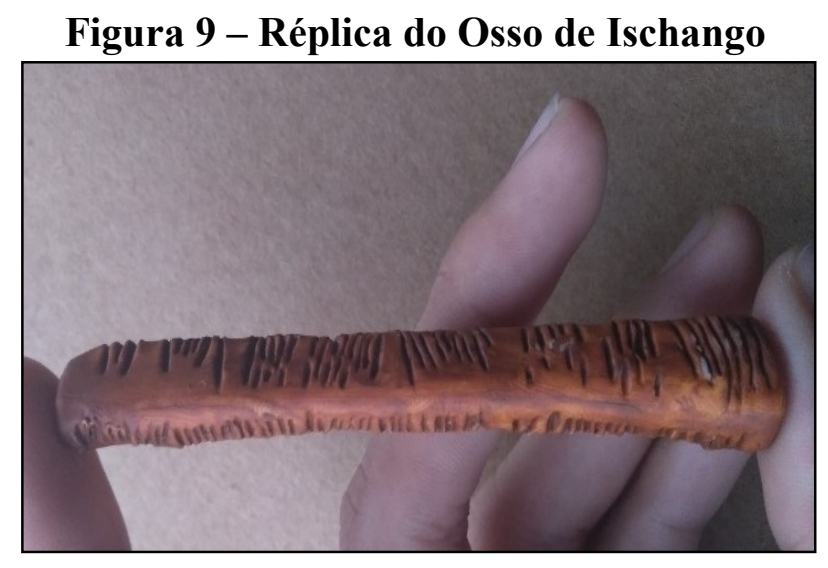

Fonte: Acervo do autor

Com este material o estudante pode perceber, utilizando as unhas, cada ranhura do objeto, e neste momento o professor irá desenvolvendo a história relembrando os números de zero a nove e posteriormente os demais. Com o entendimento dessa etapa, solicitamos ao estudante com surdocegueira que descubra quantas ranhuras existem em cada lateral do osso, e finalmente quantas ranhuras há no total. Nesse caso, de forma 
gradativa expomos a transição do número concreto para a representação do número, de acordo com conveniência de modalidades de comunicação.

A atividade exposta exige do professor que verifique todas as potencialidades que pode trabalhar, promovendo o maior acesso possivel de estímulos para o estudante com surdocegueira tornando as aulas diferenciadas e interativas.

\section{Resultados e discussão}

Neste estudo é possível reconhecer a importância da conjunção de conhecimentos de história da matemática e materiais tangíveis. Essa conjunção incentiva a produção de novas abordagens metodológicas, assim como à acessibilidade e a permanência dos alunos com surdocegueira no ambiente escolar, favorecendo o processo de construção de conhecimento.

Observou-se também que conteúdos de Matemática tendo como pano de fundo recortes históricos, apoiados por objetos tangiveis, merecem atenção dos profissionais da educação para o progresso de inclusão de alunos com surdocegueira, posto que sejam aceitos no espaço escolar e que podem assumir vários formatos, dependendo da criatividade e dos suportes que os professores o potencializem.

Percebemos a interação possivel entre professor e aluno com surdocegueira que resulta na inclusão de ambos no espaço escolar. Entendemos que trabalho com o aluno com surdocegueira exige um olhar mais aprofundado do profissional, visto que nossa percepção do que está em nosso meio vai além da visão, por esse motivo a sensibilização para a inclusão tanto do professor como do aluno é relevante.

\section{Conclusões}

O presente artigo teve como objetivo geral analisar as necessidades educacionais da pessoa com surdocegueira e apresentar uma situação da história da Matemática que possa ser atraentes ao aluno, gerando propostas de atividades que auxiliem o professor, caso encontre-se com estudantes nessas condições. 
Ao consultarmos a bibliografia do ensino de pessoas com surdocegueira percebemos que esse público apresenta uma deficiência impar, e que, para eles o tato é um canal primordial de comunicação, sendo potencializado pelo uso de materiais tangiveis, e comunicações como o Braille tátil, Tadoma e Libras Tátil.

Com o entendimento dos principais canais comunicativos das pessoas com surdocegueira, adentramos em outra área de estudo, a história da Matemática. E nesta buscamos episódios em que a matemática basilar pudesse ser associada ao lúdico a partir de contato com elementos concretos, necessários para pessoas com surdocegueira. Desta consulta observamos que os princípios de contagem primitiva valiam-se de objetos tangiveis como pedrinhas e gravetos sendo posteriormente substituídos por pequenos ossos de animais.

Da observação das situações e buscando relacioná-las, elaboramos uma proposta que utiliza os conhecimentos dos dois ramos, a surdocegueira e a história da matemática. Com essas atividades, enfatizamos a sensibilização e estímulos ao estudante, permitindo o refinamento do desempenho dos sentidos remanescentes e garantindo a atenção e curiosidade, e assim, um melhor apuro de execução de suas tarefas.

Destarte, para elaborar e aplicar essas atividades notamos duas faces da inclusão. Por um lado o aluno, que receberá suportes lúdicos, que permitirão a acessibilidade para realizar suas atividades e ter uma melhor compreensão e interpretação do que está ao seu redor, e obtendo resultados satisfatórios em seu desenvolvimento cognitivo. E, por outro lado, temos o professor, o qual tem que elaborar novas estratégias para o processo de inclusão do estudante com surdocegueira, que, por sua vez, trabalha no processo de inclusão, visto que precisa inovar suas metodologias para a realização de atividades com os alunos, analisando quais poderão utilizar ou substituir dentro do ambiente escolar.

Sabe-se que há algumas lacunas a serem superadas dentro da educação básica, referentes à inclusão de pessoas com surdocegueira, e que não serão solucionadas de um dia para o outro, mas sim de forma continua. Assim, deixamos como sugestão a elaboração de aulas com aportes Interfaces da Educ., Paranaíba, v.11, n.31, p. 650 - 674, 2020 
históricos e materiais tangiveis, sempre que possivel, pelo professor e que possam ter como objetivo o estímulo dos sentidos sinestésicos dos alunos.

Para a realização dessas atividades faz-se necessário um planejamento de acordo com o conteúdo didático que o professor pretende trabalhar. Evitando, desta maneira, um trabalho aleatório que perpasse por toda a disciplina, e que, talvez não atinja potencial significativo para o estudante no momento.

Sabe-se que a temática que cerca o presente estudo não encerrara-se neste artigo. Há muito a ser estudado em torno da inclusão de alunos com surdocegueira, apontamos a aplicação das atividades deste artigo como um desses possiveis novos estudos. Existem recursos de tecnologia assistiva e estudos com diferentes análises que permitem entender a questão da surdocegueira por outros ângulos, a luz de outros referenciais teóricos. Assim, podemos aperfeiçoar diferentes métodos e leva-los para sala de aula para que auxiliem alunos e professores no desenvolvimento eficaz de suas aprendizagens.

\section{Referências}

AUSUBEL, D. P. Adquisición y retención del conocimiento: Uma perspectiva cognitiva. Barcelona, 2002.

BARROS, J. D. Os conceitos: seus usos nas ciencias humanas.Petropolis, RJ. Editora Vozes. 2016

BEVILACQUA, M. C. Conceitos básicos sobre a audição e deficiência auditiva. Bauru. 1998

BRASIL, Lei n 10.436 Língua Brasileira de Sinais. Brasília 2002

BRASIL, Lei $\mathrm{n}^{\circ}$ 13.146 Lei Brasileira de Inclusão da Pessoa com Deficiência. Brasilia 2015

BRASIL, Parâmetros Curriculares Nacionais. Brasilia, 1998 Interfaces da Educ., Paranaíba, v.11, n.31, p. 650 - 674, 2020 
Felipe Moraes dos Santos e Elielson Ribeiro de Sales

BRASIL. [Constituição (1988)]. Constituição da República Federativa do Brasil de 1988.

BRASIL. Brasília, DF: Presidência da República, [2016]. Disponível em: http://www.planalto.gov.br/ccivil_03/Constituicao/ Constituiçao.htm. Acesso em: 1 jan. 2017

BOURBAKI, N. Éléments de mathématique, 10 vols., Paris : Editora Hermann. 1939

CAMACHO, E. H. Necessidades que perciben los educadores para atender a la población com sordoceguera ubincada em aulas especiales. Apresentado na maestria. Estudos interdisciplinarios. In: Discapacidad com énfasis in Discapacidad Múltipla y sordoceguera. Costa Rica, 2002.

CHASSOT, A. Alfabetização científica: questões e desafios para a educação. 2001

CONDE, A. J. M. Definição de cegueira e baixa visão. Rio de Janeiro 2016

CÓRDOVA, F. P. A pesquisa científica. In: GERHARDDT, T. E. e SILVEIRA, D. T. (org.). Métodos de Pesquisa. Porto Alegre: Editora de UFRGS, 2009.

DEPMAN, N. R. História da Matemática. Rússia , 1965

EVES. H. An Introduction to the History of Mathematics . 1990

FAUVEL, J; MAANEN, J. V. ICMI study onthe rolethe hitory of mathematics in theteaching and learning of mathematics. 1997

FONSECA, J. J. S. Metodologia da pesquisa científica. Fortaleza: UEC, 2002. 
Possibilidades de atividades de matemática...

GALVÃO, D,L. Estado da arte em ensino de matemática para estudantes com deficiência sensorial.

Disponível em https:/ / proceedings.galoa.com.br/cbee7/trabalhos/pesquisa-em-ensino-dematematica-estado-da-arte-em download?lang=pt-br. Acesso em: $03 / 10 / 2017$

GRUPO BRASIL. Nova definição de surdocegueira. São Paulo. 2017

GRUPO BRASIL. Surdocego pós linguístico, série surdocegueira e deficiência múltipla

sensorial. São Paulo. 2005

GRUPO BRASIL. Um guia para instrutores mediadores. São Paulo, 2008

IFRAH, G. Os Números a história de uma grande invenção. 1959

MAIA, S. M. Notas de aulas professora Shirley. 2018

MAIA, S. M. Surdocegueira e Deficiência Múltipla Sensorial: sugestões de recursos acessiveis e estratégias de ensino. São Paulo. 2010

MARIEB, E Anatomia e fisiologia humana.7a ed.. Pearson Benjamin Cummings, São Francisco. 2007

MENDES, I.A. FOSSA, J.A; VALDÉS, J.E.N. A História como um agente de cognição na educação Matemática. Porto alegre. Sulina, 2006.

MIRANDA. D. Como surgiram os números. Disponivel em: https://mundoeducacao.bol.uol.com.br/matematica/como-surgiram-osnumeros.htm. 2020.

MINAYO, Maria Cecília de Souza (org.). Pesquisa Social. Teoria, método e criatividade. 18 ed. Petrópolis. 2001

Interfaces da Educ., Paranaíba, v.11, n.31, p. 650 - 674, 2020 
MORAES, M. E. L. A leitura tátil e os efeitos da desbrailização em aulas de matemática. Pará. 2016

NASCIMENTO, F. A. A. A.; COSTA, M. P. R. da. A prática educacional com crianças surdocegas, Temas em Psicologia, v. 11, n. 2. São Paulo. 2003

NICHOLAS, J. From active touch to tactile communication what's tactile cognition got to do with it? The Danish Resource Centre on Congenital Deafblindness, 2010

PETERSEN, M. I. Avaliação e Criação de Planos Individuais para Alunos com Surdocegueira. São Paulo, 2011

POSSANI, Notas de aula de História da Matemática, 2019

SILVA. A.S. Matemática na Educação Infantil. Ed UFPA, 2006

THE NEW Encyclopaedia Britannica. Chicago. 2012

WATERHOUSE, E.J. A História da Educação do Surdo-Cego em todo o mundo. In: Anais do I seminário Brasileiro de Educação do Deficiente Audiovisual, ABEDEV. São Paulo, 1977.

WHO. World Health Organization escalas de surdez. United States. 2014 